\title{
A holistic perspective of leadership competencies
}

Pamela L. Eddy

College of William and Mary, pamela.eddy@wm.edu

Follow this and additional works at: https://scholarworks.wm.edu/educationbookchapters

Part of the Community College Leadership Commons

\section{Recommended Citation}

Eddy, Pamela L., "A holistic perspective of leadership competencies" (2012). School of Education Book Chapters. 35.

https://scholarworks.wm.edu/educationbookchapters/35

This Book Chapter is brought to you for free and open access by the School of Education at W\&M ScholarWorks. It has been accepted for inclusion in School of Education Book Chapters by an authorized administrator of W\&M ScholarWorks. For more information, please contact scholarworks@wm.edu. 


\begin{abstract}
This chapter argues for the use of clusters in thinking about the AACC competencies. Four clusters are presented: inclusivity, framing meaning, attention to the bottom line, and systems thinking. Overarching these clusters is the need for contextual competency in which leaders align their approaches based on their college's context.
\end{abstract}

\title{
A Holistic Perspective of Leadership Competencies
}

\author{
Pamela L. Eddy
}

The passage of time since the creation of the six competencies by the American Association of Community Colleges (AACC) allows for critical reflection of the original list. This chapter reviews data collected from twelve community college presidents and a variety of campus members (Eddy, 2010). The data for this study included interviews with each of the case site presidents, members of the leadership team, and faculty leaders, for a total of seventy-five interviews. The dozen presidents in this study lead a variety of types of institutions, ranging from small rural campuses to large, multicampus urban colleges. The presidents differed as well on the number of presidencies they held and their years of service in the top-level position. The only variable of consequence for how the presidents implemented the competencies was their length of tenure as president (Neumann and Bensimon, 1990). The longer their service, the greater breadth they had in using the competencies given their experiences and resulting learning due to feedback from their actions.

As noted in chapter one, in 2005 AACC published a set of six competencies created by consensus to target skills central to leading the community colleges of the future. This listing provided individuals seeking top-level positions a road map for development and helped institutions target areas in training topics for in-house grow-your-own leadership programs. As with any type of listing, however, an inherent danger is devolution to a mere checklist versus viewing the competencies as a general 
starting point. The next section reviews how the presidents in this study used the individual competencies.

\section{The Competencies in Action}

Each of the presidents in this study utilized the AACC competencies to some extent. In particular, organizational strategy, with its focus on management issues and operations, was an area frequently addressed first when the presidents initially arrived on campus. Visible outcomes were apparent as new presidents implemented new organizational reporting structures or created strategic plans. Often, the creation of a new reporting arrangement established a more hierarchical structure that embedded power more centrally with the president (Morgan, 2006). The strategic planning activities, however, served to underscore collaboration and consensus building. As one president commented, "Our strategic planning sessions were interactive, more of a dialogue and smaller groups." These sessions fostered openness and a connection for the campus members with the outcomes. Campus members saw these types of efforts as most successful, however, when plans resulted in actual changes in practice versus planning exercises whose final planning documents sat on a shelf. Existing campus culture and college history influenced how the operationalization of plans occurred and how staff reacted.

The challenges of fiscal constraints facing the colleges resulted in all the presidents focusing on resource management skills. How leaders manage personnel and physical plant operations relies heavily on ethical leadership. Presidents must account for use of funds and support their decisions of resource allocation. The expansion of college missions coupled with the simultaneous cuts in state funding resulted in case site presidents making tough decisions. How presidents framed this situation, however, differed among those in the study (Neumann, 1995). In essence, approaches focused on the glass as either half-empty or half-full. As one president reflected, "Focusing on dealing with the budget crises in such a way that everybody is kind of focusing on a bigger picture, not just the 'oh poor me, they took my money away and I can't travel' but the fact that we have an important job to do and the college needs us, we're going to serve our students and so forth." Another president also referenced the need to frame the situation for others: "My role is to probably help people here understand that even though we've got to tighten our belt and we're having to do these undesirable things, it's going to be okay." Countering these examples, campus members on one campus noted constantly being asked to do more with less and seeing no relief in sight. The manner in which the presidents spoke of resources on campus influenced campus reactions (Neumann, 1995).

How leaders communicate within the campus and with outside constituents matters. A critical element in communication is the art of listening 
(Hoppe, 2006). The first opportunity a leader has to communicate is during the initial job interview. Clues are given during these interactions with campus staff, board members, and community constituents. Sitting presidents were often able to note in retrospect the messages they missed during this first visit on campus and to understand more clearly in hindsight how the first campus visit presented aspects of the campus's culture. As one president reflected, "Sometimes you have to put four, five, six pieces together. You talk to different people and then you put it all together." Seeking out divergent perspectives helps create a richer understanding of campus realities. Communication styles varied among study participants, with some favoring writing to connect their ideas to the campus and others preferring to talk with groups, either in small group settings or with larger groups. Consistency in the messaging was critical to ultimate success. On some campuses, messaging was successful as several campus members could articulate the strategic plan and mission of the college using similar metaphors and stories (Bolman and Deal, 2008).

Decreases in funding for community colleges make partnering with others enticing. Collaborations, however, have brought in a wider range of stakeholders that include universities, industry, and community agencies. Indeed, many state policymakers include collaborations in their planning to reform educational practices and efforts to link educational sectors across the P-16 continuum (Closing the Expectations Gap, 2011). External collaborations for the participants involved linking with businesses to fulfill training needs, working on regional economic development initiatives, or working with local school districts to establish educational ladder programs. Equally important for leaders were internal collaborations. One new president noted the challenges she faced when first arriving on campus: "All these deans had carved off their little fiefdoms. And they were all fighting with one another and their staff were fighting with one another." She worked to build a collaborative culture, which required good communication skills as well as an ability to work well with individuals.

Advocacy, espoused by participants as a critical competency, was inherent in the work of both new and seasoned presidents. Advocacy was apparent in both the words and actions of the presidents. Many of the participants used strategic planning as an opportunity to support the missions of their institutions. College websites also served as a vehicle for advancing the college's mission. Presidents were visible at community events and used these opportunities to network with various stakeholders to garner more support. As one president commented, "The college typically views itself as being apart from the region, and I'm trying to build the image in the minds of our faculty and staff that we are the region. And without us, it will not change." For rural colleges in particular, links to the community were heightened due to their small population, which resulted in everyone's knowing one another. Advocacy in these instances differed from urban locales in which competition for public attention was harder to obtain. 
The final AACC competency is professionalism. As college spokespersons, the presidents always represented more than merely themselves as college leaders. Indeed, they were the college for many they encountered. This public spotlight resulted in a closer inspection, especially for the presidents of color and female presidents. Leadership development and mentoring served a critical role in preparing presidents for their role, and in turn influenced how these sitting leaders helped train others on their campuses. Leaders modeled expectations and helped in developing the next generation of community college leaders. As one female minority president noted of her advisement to others, "Develop a confidence that you can do it. I think white males are raised that way. I think it is a kind of entitlement. I've never been in a position to feel or think I can achieve just because it's an entitlement; I've had to work for everything." Central to this mentoring is developing what one president referred to as "survival skills." A critical component in this skill bank was a professional network. As noted in Chapter Two, national leadership development training programs embed mentoring and networking as part of their programs. Seeing how others lead and learning from the mistakes of others provide valuable learning opportunities. Visits to other campuses also help illustrate a range of ways to solve problems and illustrates how problems on any one campus are not unique.

Despite the comprehensive skill set outlined in the AACC competencies, missing from the list is the importance of environment. I have argued that the current AACC competency listing needs to include cultural competency (Eddy, 2010). Here, competency requires understanding the college culture and reading the context of what is valued. This concept is different than historic notions of cultural competency that deal with issues of diversity, so, to avoid confusion, I will refer to this now as contextual competency. Knowing more about the campus culture allows for the creation of organizational strategies aligned with existing frameworks of what works and acknowledges the history of the institution.

A sense of fit between the college and the leader emerged during the site visits. A good fit might exist due to a leader's past experiences and skill set and the current demands on the college. Some campus members noted the need to hire a "go-getter" to initiate institutional changes. Others sought to counteract the type of leadership exhibited by the last president.

Leaders who possessed a competency for reading and interpreting the campus context and culture hit the ground running. In part, acknowledging and recognizing campus traditions and history helped to engage the campus in change. One campus member described her campus as a "dysfunctional family," which underscored for the new president a need to build community and to start new traditions. Two of the male presidents who had long careers as leaders could best be described as "good ole boys." Part of the reason for their success on their new campuses was the level of participation they elicited from campus members and how they valued leadership 
throughout the institution. But, at the end of the day, it was clear that these leaders understood that they were responsible for making the tough decisions on campus. Knowing the culture and context of the campus helps leaders achieve desired changes. Because many community colleges are part of larger district cultures, leaders often must figure out how to work within the culture of their own college as well as that of the larger system.

\section{The Competencies as Clusters}

In the analysis of the data from this study, it became apparent that many of the competencies operated in tandem, and patterns of alignment came forward. For instance, the competency of resource management often aligned with organizational strategy, and communication aligned with collaboration. Present in all of the clusters was the application of contextual competency. Viewing the competencies more holistically provides a different perspective and approach to leadership development and leadership enactment on campus. In many ways, these connections to campus context harken to notions of situational leadership. What differs in this case is that the focus is no longer on how best to address a campus context by selecting the appropriate leader for the time, but rather on how to recognize that individual leaders can acquire a wider range of leadership approaches to allow for expansion of existing schemas that provide more frames to guide their actions (Bolman and Deal, 2008). Viewing leaders from a multidimensional perspective (Eddy, 2010) provides more complexity to aid understanding of leadership in what is now a more complicated campus environment.

Inclusivity. The cluster of inclusivity builds on the skills of communication and collaboration. Here, collaboration moves beyond merely asking campus members for contributions on ad hoc teams toward relationships that involve shared leadership. Communication changes from dyadic exchanges to shared dialogue. One of the study presidents who utilized this cluster referenced a team metaphor to illustrate the concept, but was clear in his intention for inclusivity when he stated, "I'm not a team owner. It's ours. We are all in this together." The president's description underscored how roles change on the team, in particular the role he played. He did not view himself as the sole arbitrator for the group; rather, he saw his role shifting depending on the needs of the group. This changing role highlights the contextual competency he drew upon in his leadership. His notion of inclusivity built on a platform of mutual values, which harkens to ideals associated with transformational leadership.

Associated with the inclusivity cluster is the ideal of organizational learning. Drawing on the expertise of multiple campus and external stakeholders assumes that communication venues are using feedback loops that allow organizational leaders an opportunity to test assumptions about operations and to change campus direction based on this feedback. One campus member described operations on her campus that used consensual decision 
making. She stated, "We have 'imagine luncheons,' which are vision luncheons where the president updates us and she praises particular initiatives, individuals, pins new faculty and employees who have come on." This person added how quick the president was in responding to e-mail, which contributed to the feeling of transparency in communication on campus. This process helped support organizational learning on this campus and made campus stakeholders feel included in the process.

Framing Meaning. Framing, as the name implies, involves campus leaders helping to make sense and interpret campus events for others. Here, one might imagine a president using a picture frame to focus campus attention on a particular view or perspective. Undergirding the cluster of framing meaning are competencies in organizational strategy, communication, collaboration, and advocacy. Contextual competency is included, as it is in the other clusters, but here the role of understanding campus needs and the culture is pivotal to the cluster. Knowing what the campus needs helps the president decide on what is most important to frame. Framing communicates the overarching organizational strategy to campus members, and this strategy is developed collaboratively.

One of the new presidents in the study found herself on a fractured campus in which faculty held little trust in administration, ethical issues emerged during a campus self-study, and deans sought to operate as silos within the larger institution. The president's first action was to change organizational reporting to both symbolize and frame a different orientation to campus operations. She created a new organizational reporting structure that showed more cohesiveness of operations and instilled new reporting routes. This action allowed the campus to "see a change." Next, the president worked with a cadre of faculty to build trust and better understand the culture of the institution. This relationship building and collaboration created an environment more conducive to operationalizing the campus's strategic plan.

Two other leaders who operated using the framing meaning cluster needed to rebuild trust on their campuses. They sought to frame meaning by conducting a series of one-on-one or small group meetings with faculty and staff. This exercise let these new leaders quickly get a sense of what was important to the campus community and to gauge the best mechanisms for relaying messages about future direction. While both leaders were careful to acknowledge the past history of the campus, they realized that in order to make progress in the future, the campus environment needed to change. Framing meaning for the campus meant creating a new image of how campus members would interact, both with each other and with larger system offices.

Framing meaning involved presenting a vision for the college that was based on collaboration and dialogue with campus stakeholders. Here, listening was central to the communication process (Hoppe, 2006). Leaders also served as internal advocates for their campus members and external 
advocates for their colleges. An important element in the framing process was a consistent message and shared understanding of organizational strategy. In many ways, this singular messaging represented cohesiveness on campus and focused the attention of campus actors to move in the same direction.

Attention to the Bottom Line. The current national context of fiscal exigency creates internal challenges for many community college campuses. For some colleges, extreme resource constraints drive all other decisions as campuses struggle to meet their multiple obligations and missions. Central to this cluster are the competencies of resource management, organizational strategy, and advocacy. Contextual competency focuses on understanding the fiscal climate and on how limited resources may align with the college's largest demands. Decisions are driven by an attention to bottom-line costs and achieving the greatest outcomes possible with the limited resources.

One of the campus leaders using this cluster orientation led a campus that had been historically underfunded and was part of a larger system. He advocated within the system structure for more resources and used these resources to attend to the direst needs. Campus perception was that "we got the short end of the stick." Ultimately, the president was able to secure additional resources for his campus; by his account, one of the reasons he was successful in this endeavor was that he had prior presidential experience and was able to draw upon his wider network and the competencies acquired over time to achieve this outcome. He also understood the need to develop a campus vision and organizational strategy to help in deciding how resources could be spent best. Once this vision was crafted, he advocated for resources that focused on achieving the central initiatives of the strategy.

For one of the other campus leaders, financial problems were also an issue. Here, the president worked to educate her campus on techniques to increase resources without significantly changing operations. Namely, she advocated for students to take a full-credit load of course work each semester. The funding formula in the state rewarded campuses with higher student credit hours, and communicating this operational strategy to faculty advisors provided a quick fix. The president regularly communicated with campus members to enhance their understanding of the resource issues and thereby build consensus in final decisions as stakeholders understood the rationale behind them. Seeing success in the changes advocated on campus provided immediate feedback and built trust on campus as well.

Systems Thinking. The final cluster of systems thinking also has a focus on organizational strategy and communication, but additionally includes professionalism. A higher-order organizational perspective allowed those using this orientation ways to see connections between actions and reactions, even when not most evident. Longer-serving campus presidents used this cluster most often. Not only did previous experience help guide 
these presidents, but they also possessed an understanding of cause and effect within the campus organizational system.

The longevity of these leaders also meant that they had favored schemas for their own leadership approaches (Eddy, 2010). One president operating from this perspective turned to the use of technology in teaching and learning as a mechanism to advance the campus mission. His background in the business community also meant that he valued an entrepreneurial approach to academics for both faculty and students. Even though he had this vision for the campus, he sought to build broad-based consensus for the proposed programming. He relied on building his professional network and his own orientation to learning to help support this campus change. His system view of problems allowed him to see connections between academics, campus operations, student learning, and community outreach. This type of connective thinking provided the campus with various means to achieve the vision for the college.

Another president utilizing this perspective used the college's mission statement as a vehicle to advocate and promote the changes he envisioned. Built into the mission statement was a commitment to lifelong learning opportunities and innovative partnerships, which clearly links to the AACC competencies of professionalism and collaboration. Using the agreement and buy-in for the mission statement, a five-year strategic plan was devised. Unlike typical strategic plans that sit on a shelf, this campus actively used their plan in making decisions and marking progress. Because of the detail in accountability and reporting on progress throughout the year, campus members could see clear links with actions and outcomes. Monthly leadership meetings provided the opportunity for feedback into the system and better recognition of how actions by various campus entities were connected. The campus was readily positioned to advocate its mission and strategy as it had a television station on campus. This venue allowed the president ready access to college stakeholders and served as a vehicle for advocacy with both external and internal stakeholders.

\section{A Look to the Future}

The creation of a new way to think about the AACC competencies is illustrated in Figure 3.1. In this model, contextual competency resides as a core element and is present in all of the cluster approaches. Contextual competency links to individuals' past experiences and emerges from underlying leadership schemas (Weick, 1995). How leaders learn to lead is based on what they know has worked for them in the past and how they naturally operate given their individual preferences (Eddy, 2010). For instance, some individuals are natural networkers and enjoy connecting people and ideas, whereas others are drawn to analytical investigation of problems and strategies. Despite these natural inclinations, all leaders can learn (AACC, 2005). 
Figure 3.1. Holistic Competencies

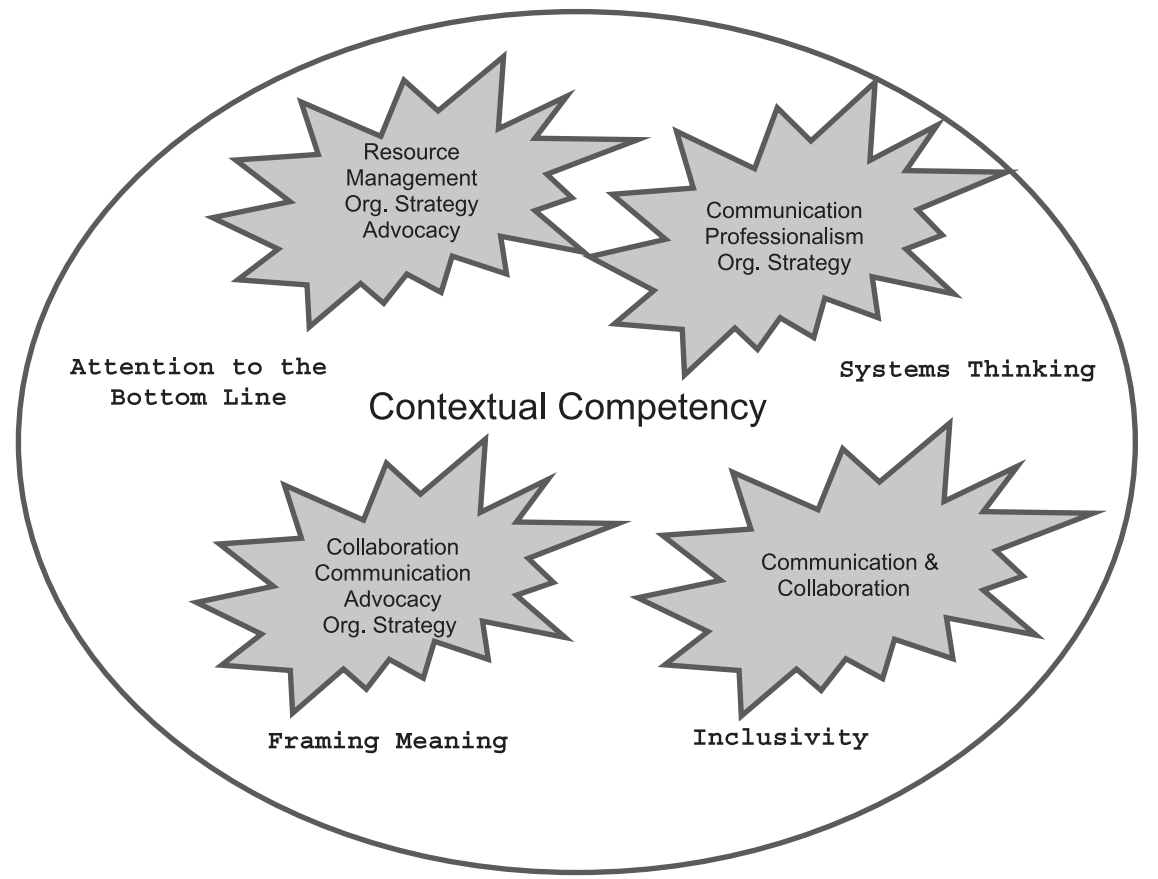

Each of the clusters in the model utilizes two or more of the original AACC competencies. Natural connections emerge among several of the groupings, such as resource management/organizational strategy and communication/advocacy. Because the groupings share many of the individual competencies, leaders can move among the various clusters with relative ease once they have done an environmental scan of the college context to determine what is needed. Thus, it is erroneous to say that one of these clusters is more valued than another. Instead, the best approach by a leader depends on the situation they face. As Neumann and Bensimon (1990) found when researching college presidents, a multiple-framed view of organizations by leaders develops with experience and with need. They found that community college leaders in their study were most likely to use more than one organizational frame of operations, as were senior leaders.

Seasoned leaders draw from their previous experiences of what worked and what did not as they arrive on a new campus. Here, they make adjustments based on the new setting and on feedback to their actions. New leaders, however, test the waters differently given their limited experience base in the top-level position. Moreover, leaders may see the clusters operating differently when viewed through the lens of race and gender as others may have stereotyped or prescribed roles ascribed to particular leader character- 
istics. Campus perceptions of leadership actions are viewed based on expectations of how women or leaders of color should act (Griffin, 1992).

Using a more holistic approach to the competencies affords an opportunity to expand thinking about leadership in community colleges. Instead of narrow definitions of leadership, this broad perspective creates a chance for picturing a variety of types of leaders as options to lead two-year colleges. Thus, the anticipated turnover in community college leaders due to retirements (Weisman and Vaughan, 2007) may make way for more presidents of color and women to ascend to these top-level positions.

Leadership developers and graduate program faculty can take note of this broader conceptualization of the AACC competencies and embed ideals of connections among the competencies into their training and classes. For instance, as Wallin points out in Chapter Two, the Future Leaders Institute already builds its training development from the existing competencies. Inserting scenarios for the participants to think about how to mix and blend the competencies based on campus needs and on the individual's leadership orientation would help new leaders when they arrive on campus. Realizing in advance how the competencies operate in clusters can contribute to a faster learning curve for leaders and provide a more complex analysis of any given situation. The increased complexity of today's community colleges requires adaptations by leaders to this changing environment and a more holistic view of the competencies required in leading.

Preparing to use the competency clusters in practice requires a sense of self-awareness and reflection on which of the initial six competencies one aligns with. Next, an understanding of the current environment aids in determining which of the clusters is most effective. The following points serve as an initial guide to using the clusters in practice:

- Identify your go-to competencies from the AACC listing (organizational strategy, resource management, communication, collaboration, community college advocacy, professionalism).

- Conduct environmental scanning of your current/new institution to determine the type of competency cluster required based on the current context and desired change.

- Assess which of the competencies you must augment to make your competency cluster most effective. For instance, if you determine that a framing cluster is required, but you note that your personal orientation relies on organizational strategy and advocacy, work on becoming more skilled in the areas of collaboration and communication.

- Build competencies in your staff through professional development to help support the overall cluster in practice at the institution and to create capacity. All campus members serve as emissaries of the college in the community and with stakeholders, thus it is critical to prepare them to represent your agenda well. 


\section{References}

American Association of Community Colleges. Competencies for Community College Leaders. Washington, D.C.: American Association of Community Colleges, 2005.

Bolman, L. G., and Deal, T. E. Reframing Organizations: Artistry, Choice, and Leadership (4th ed.). San Francisco: Jossey-Bass, 2008.

Closing the Expectations Gap. Washington, D.C.: Achieve, American Diploma Project Network, 2011.

Eddy, P. L. Community College Leadership: A Multidimensional Model for Leading Change. Sterling, VA: Stylus Press, 2010.

Griffin, B. Q. "Perceptions of Managers: Effects of Leadership Style and Gender." Paper presented at the Annual Meeting of the Southeastern Psychological Association, Knoxville, Tenn., 1992.

Hoppe, M. H. Active Listening: Improve Your Ability to Listen and Lead. Greensboro, N.C.: Center for Creative Leadership, 2006.

Morgan, G. Images of Organizations. Thousand Oaks, Calif.: Sage, 2006.

Neumann, A. "On the Making of Hard Times and Good Times." Journal of Higher Education, 1995, 66(1), 3-31.

Neumann, A., and Bensimon, E. M. Constructing the Presidency: College Presidents' Images of Their Leadership Roles, a Comparative Study. Journal of Higher Education, 1990, 61(6), 678-701.

Weick, K. E. Sensemaking in Organizations. Thousand Oaks, Calif.: Sage, 1995.

Weisman, I., and Vaughan, G. The Community College Presidency: 2006. Washington, D.C.: American Association of Community Colleges Research Brief No. AACCRB-07-1, 2007.

PAMELA L. EDDY is an associate professor and area coordinator in Educational Policy, Planning, and Leadership at the College of William and Mary in Williamsburg, Virginia. 